\title{
Business Process Re-Engineering and Profitability in the Nigerian Oil and Gas Industry: The Mediating
} Influence of Operational Performance

\author{
Olawumi Dele Awolusi ${ }^{1}$, Olusegun Sulaiman Atiku² \\ ${ }^{1}$ Kampala International University, Kampala, Uganda \\ ${ }^{2}$ University of KwaZulu-Natal, Westville, South Africa \\ awolusi.olawumi@kiu.ac.ug, atiku@ukzn.ac.za
}

\begin{abstract}
The aim of this study was to operationalize and test a conceptual model to measure the effect of Business Process Re-engineering (BPR) implementation on profitability in the Nigerian oil and gas industry. Based on a framework from Al-Mashari and Zairi, these objectives were achieved using the following procedures: reliability and validity analysis, factor analyses (exploratory factor analysis-EFA and confirmatory factor analysis-CFA) and Structural Equation Modelling (SEM). The model contrived therefore confirmed the positive influence of BPR on profitability, as well as the mediating influence of operational performance in the Nigerian Oil and Gas industry. Specifically, the structural model shows the positive effect of organizational structure and IT Infrastructures on both profitability and operational performance. However, SEM failed to establish the relationship between management competence and support and profitability. The study is expected to enhance the adoption and successful implementation of BPR programmes in the oil and gas industry.
\end{abstract}

Keywords: Business Process Re-engineering; CSFs; Profitability; Operational Performance, structural equation modeling.

\section{Introduction}

It is often argued that there is no generally agreed definition of business process re-engineering (BPR). However, Khong and Richardson (2003), define BPR as an approach to attain radical improvement in various performance matrixes. The objective of BPR is to look for innovative methods to combine people, tasks, and materials and restructure information technology in all the processes to achieve organization's objectives (Asikhia and Awolusi, 2015; Hammer, 1990). BPR has gained significant attention as a management technique strategy during the past years. This might not be unconnected with the increasing challenges of businesses worldwide, where organizations are expected to respond swiftly in making strategic changes to sustain their competitive advantage (Ringim, Razalli, and Hasnan, 2011; Khodakaram, Mohammad, and Ahmad, 2010). The current economic recession, globalization, and rapid development of information technology (IT) often justifies the present scrabbles for new strategies for success in a dynamic environments (Al-Mashari and Zairi, 1999; Salaheldin, 2009). In addition, many oil and gas companies now strive to reduce costs and increased profitability to create a competitive strategy (Hammer and Champy, 1993). Accordingly, most oil and gas companies seek to adopt management techniques that have been successful in another place, via radical improvement (Al-Mashari and Zairi, 1999; Salaheldin, 2009). One of such management techniques is BPR (Salaheldin, 2009).

BPR is a fundamental rethinking, as well as, a drastic restructure of processes to realize improvements various performance indices, like cost, quality, speed and service (Ozcelik, 2010; Ranganathan, \& Dhaliwal, 2001; Al-Mashari and Zairi, 1999). There has been fundamental changes in the world oil and gas industry (Cabin and Grant, 1996) in the last twenty years: the increasing influence of producer countries, nationalization of oil reserves of the majors (Exxon, Shell, and BP), increasing pressure from investors and the financial community for improved return to shareholders, the increasing popularity of state-owned companies have contributed to BPR adoption and implementations (Al-Mashari et al., 2001). The key features of business re-engineering by the oil and gas companies are: reduction in excess capacity, reduction in personnel, reorienting their goals around shareholder value maximization, shifting from geographical organizational structure to worldwide product divisions (Adeyemi and Aremu, 2008; Ringim et al., 2011). However, despite the noteworthy growth in BPR adoption, most of the companies implementing BPR do not often accomplish their projected result. Studies like Hall et al. (1993) and Chiplunkar at al. (2003) estimate 50-70 percent failure rates. Many of these previous studies sustained these mixed findings and recognised the prospect for conducting studies that will ascertain the critical factors for BPR implementation success. 
As well as establish the relationship between operational performance and organizational performance (Hammer and Champy, 1993). In addition, this high failure rates, according to Ringim et al. (2011) is ascribed to poor implementation of BPR. Consequently, some critical success factors must be identified and analyzed for successful BPR implementations (Hall et al., 1993; Ringim et al., 2011). In addition, establishing the relationship between major BPR imperatives and business performance as a way of forestalling BPR project failure becomes important, thus investigating the CSFs of BPR and profitability could be a step in the right direction (Ringim et al., 2011). Moreover, measuring CSFs of BPR scientifically is imperative, because, what can be measured gets done well, with the possibility of repeated fed back and rewards (Fields \& Atiku, 2015; Mustapha, Fakokunde and Awolusi, 2014; Asika and Awolusi, 2013). Khong and Richardson (2003) also believe that a deeper appreciation and understanding of CSFs of BPR through scientific inquiry is desirable. The intention of the research on which this study is anchored was to test a conceptual model to measure the effect of the CSFs of BPR on organizational performance in the Nigerian oil and gas industry using multivariate analytical technique. The third section discusses the methodology. The paper starts with the identification of the various CSFs of BPR in literature.

They then categorised these CSFs into various subgroups, similar to Al-Mashari and Zairi (1999) categorisation. In addition, various views on BPR implementations and its effects on business performance (organizational and operational performances) were tested to show the imperatives of successful BPR efforts. The study shows the need for a conceptual model to measure the success of BPR efforts in the oil and gas industry. Consequently, the main objective of this study was to operationalize a BPR model, based on a conceptual framework developed by Awolusi (2013), and to test the contrived model, by examining specific relationships between the CSFs of BPR and profitability in the Nigerian oil and gas industry. Moreover, the study also investigated the mediating influence of operational performance on profitability of companies operating in the oil and gas industry. This study was motivated by the submission of Awolusi (2013) and Khong and Richardson (2003) that, despite some research attempts, a model to test the success of BPR implementation in the oil and gas industry has not been fully established. The second section of this study discussed the conceptual framework developed by Awolusi (2013). The fourth section analyses the results and discussions, by focusing on the operationalizing and testing of the conceptual framework in an attempt to recommend an improved model to measure BPR implementation success in the oil and gas industry.

\section{Literature Review}

The Conceptual Model: BPR approach was developed by practitioners and emerged in the early 1990s; consequently, BPR can mostly be linked with the most relevant theoretical areas. BPR can be inferred from prevailing theories within: organization theory, Marketing, Internationalization theories and Informatics (Ahmed et al., 2007; Tilley, 1996). This is due to the fact that much of BPR focuses on the following as far as the organizational aspects is concerned: organizational change, organizational culture \& power, organizational complexity, theories on departmentalization, and human resource management (Ahmed et al., 2007; Maldonado, 2009). BPR, also called business process reorganization or flow innovation, is a concept in the change management domain (Ahmed et al., 2007). Consequently, this research is anchored on change management theories. According to the theory of constraints (TOC), a change management theory, the objective is to improve organizational performances undergoing series of interdependent processes (Ahmed et al., 2007).

It scrutinizes the process as complete system, recognizing and resolving the bottlenecks, or constraints (Iles and Sutherland, 2001). Theory of Constraints is one of the three examples of process Modelling approaches. Others are influence diagrams and process flows. According to Davenport (1993a), the consideration of BPR posits competitive advantage and customer focus, and "value-adding" as important factors determining business processes (Khong and Richardson, 2003; Maldonado, 2009). Under internationalization perspective, are resource-based view, institutional theory, transaction cost analysis (TCA), and Dunning's eclectic framework. The resource-based theory is aimed at improving the core competence of the organization in the process of developing sustainable competitive advantage (Richard, 1992). The resource-based view (RBV) places firms' resources (valuable) as a critical ingredient for achieving competitive advantage (Hoopes, Madsen, and Walker, 2003; Porter, 1980; Rumelt, 1991). The interaction among institutions, organizations, and strategic choices are the main focus of institutional theories. 
The relationships between institutions and organizations (Smith, 2003; Brouthers and Hennart, 2007), is posits to result into strategic choices for the successful implementation of the BPR (Smith, 2003). Transaction cost analysis posits that BPR efforts are implemented in most organisations to reduce the transaction costs (Ringim et al., 2011). The approach links some environmental factors with human factors to analyse how firms can categorize transactions to lessen the costs of transactions (Ahmed et al., 2007). Lastly, Dunning (1993) proposes that the three traditional perspectives were singly incomplete in explaining the mode to internationalization BPR as a management techniques (Brouthers and Hennart, 2007). Dunning's eclectic theory on the other hand identifies ownership, location and internalization advantages. Dunning's eclectic theory try to elucidate the transfer of firm-specific ownership advantages (Brouthers and Hennart, 2007), towards the successful implementation of BPR. Informatics, as an imperatives in the use of information technology (IT) for supporting process-based firms, is posited on the basis that IT is required to attain the best outcomes in BPR implementation (Davenport, 1993b; Ovenden, 1994); most importantly, the redesign stage of BPR implementations (Bhatt, 2000).

The Conceptual Model: Based on a framework from Al-Mashari and Zairi (1999), Awolusi (2013) made an attempt to advance a framework to measure the success of BPR efforts in the Nigerian oil and gas industry. The study adopted a survey research design, via the use of questionnaires to elicit information from the respondents. The population was made up of senior and management employees in the production and exploration sector of the Nigerian oil and gas industry. To establish the validity and reliability of constructs, questionnaires were first of all distributed to few experts and three professors in management studies as a pilot test. Recommendations from these set of respondents were analysed after the required modifications and then, the final validated version was acknowledged. The study adopted a multi-stage sampling technique in selecting the participating companies (Exploration and Production, Multinationals and Local companies) and the final respondents in the participating companies. In all, a total sample size of 550 was arrived at.

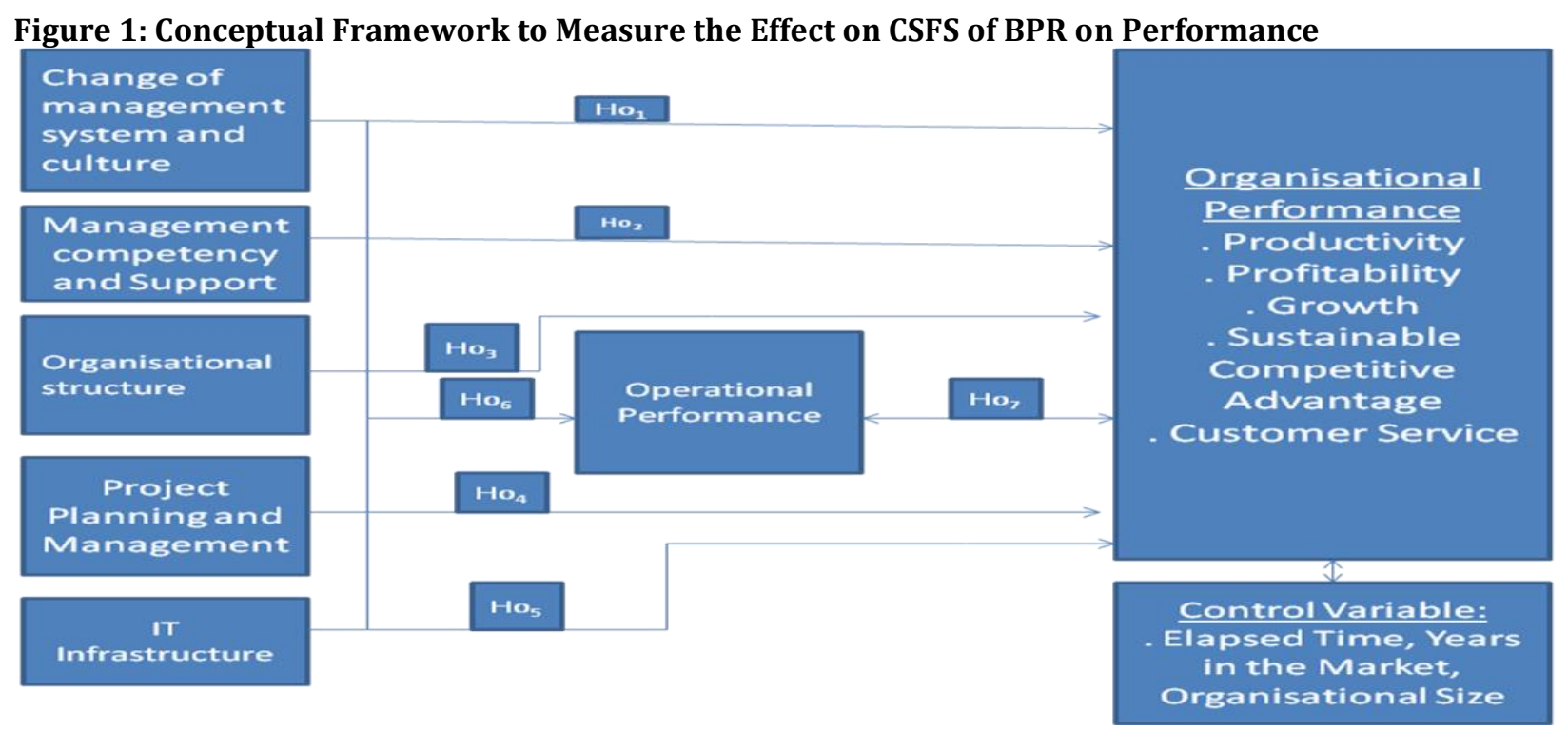

Source: Adapted from Awolusi, 2013a

Although the various measures incorporated in the proposed model (figure 1) was corroborated and adopted from past studies, nevertheless, each item were evaluated, discussed, and adapted by management experts in BPR adoption and implementations in the Nigeria oil and gas industry.

Critical Success Factors (CSFs) of BPR: There are varied meaning of CSFs of BPR in literature, however, Ahmed et al. (2007) defined CSFs as those things a firm must get right for the implementation of BPR to be successfully. In focusing his study, Awolusi (2013) listed some factors (Figure 1), as derived from various studies on BPR implementation. Consequently, the factors were categorised into five subgroups, similar to AlMashari and Zairi (1999) categorization. These dimensions were: Change of management systems and 
culture; Organisational structure; management competency and support; IT infrastructure; and project planning and management.

Operational Performance and Organizational Performance: As a mediating variable, operational performance was defined as the internal performance of a company in terms of waste reduction, cost, quality improvement, improving employee relations, flexibility, productivity improvement and operating procedures (Salaheldin, 2009). This construct was termed primary measure, because it trails directly the implementation stage. On the other hand, organizational performance, a secondary measure, was initially represented by financial measures such as profitability, growth, productivity; and non-financial variables such as customer services and sustainable competitive advantage. However, many studies have established the link between various performance indices and BPR efforts (Asika and Awolusi, 2013; Awolusi, 2013b; Awolusi, 2013c; Ascari et al., 1995; Smith, 2003). These studies were aimed at helping firms improve their competitiveness, by improving operations and processes. In addition, the output of these studies demonstrated the important role of BPR implementation efforts in improving various performance measures (e.g. operational and profitability). Therefore, it is hypothesized that:

Ho1: Critical success factors of BPR has no significant relationship with operational Performance

$\mathbf{H o}_{2}$ : Critical success factors has no significant relationship with profitability

$\mathbf{H o}_{3}$ : Operational performance has no significant difference with profitability

These hypotheses were motivated by Khong and Richardson (2003) and Ozcelik (2010) postulations on the effect of the BPR on operational performance, and its consequential relationships with profitability.

\section{Methodology}

The objective of the research reported in this paper was to operationalize a model of a successful BPR implementation, and to test the model, via modeling (using structural equation modeling-SEM) the CSFs of BPR on performance measures in the oil and gas industry. These objectives were achieved using the following procedures: factor analyses (exploratory factor analysis and confirmatory factor analysis) and Structural Equation Modelling (SEM) (Asikhia and Awolusi, 2015; Mustapha et al., 2014; Asika and Awolusi, 2013; Awolusi, 2013b; Awolusi, 2013c). Since the focus of this paper was the analysis of what was done after the development of the conceptual framework, consequently, additional analysis was conducted to determine the causal path analysis using the Pearson's product correlation coefficient (PPMC) and SEM. The first stage of this study was to develop a conceptual framework to measure the efficacy of BPR implementations in the oil and gas industry using a survey research design. Consequently, exploratory factor analysis (EFA) was used because the number of CSFs of BPR that were necessary to explain the interrelationships among the set of variables were not known, in the Nigerian context, and also the need to determine the underlying dimensions of the constructs (Fields \& Atiku, 2015). Based on a framework from Al-Mashari and Zairi (1999), Awolusi (2013) conceptual framework was developed to measure the success of BPR implementation efforts in the Nigerian oil and gas industry.

From a population of 55,305, 550 questionnaires were administered to randomly selected respondents in the participating companies, with 422 completed questionnaires returned (Asikhia and Awolusi, 2015). 20 responses were discarded, due to incorrect fillings, leaving 402 valid responses for statistical analysis. This represented a response rate of $62 \%$. Again, the target population and sample size were justified based on the fact that the participating companies represent over $85 \%$ of the total oil production in Nigeria (Asikhia and Awolusi, 2015). In items measuring CSFs of BPR implementation, participants were asked to rate the degree of effectiveness of 32 items measuring their company's BPR strategies. In business performance, they were asked to rate 6 and 26 variables in relation to their companies' operational and organizational performances respectively. The questions were based on an interval scale from 1 to 5 . In the scale 1 represents strongly disagree, 2 denotes disagree, 3 represents neither disagree nor agree, 4 denotes Agree, and lastly, 5 represents strongly agree and n/a (not applicable) was added so as not to force the respondents. The data were analyzed with the statistical package for social scientist (SPSS) version 15 and AMOS 23. 


\section{Results and Discussion of Findings}

Reliability and Validity Analysis: The 402 valid responses were subjected to a principal component factor analysis using a Varimax normalized rotation. The exploratory factor analysis produced a variance explained of $64 \%$, indicated that the measuring tool to measure CSFs of BPR was valid. Cronbach's alpha $(\alpha)$ was used to test the reliability of the measuring tools. The rule of thumb suggests 0.7 to be the acceptable value (Hair et al., 1995). In addition, composite reliability (CR) and average variance extracted (AVE) were also established. Consequently, the results were above the recommended 0.7 and 0.5 for CR and AVE respectively (Hair et al., 1995). These represented a robust reliability and internal consistency of the constructs (Hancock \& Mueller, 2001). Furthermore, based on the extraction from the principal component analysis, all the variables comply with the assumption of no perfect multicollinearity. VIF and Tolerance coefficients were also within the acceptable range, to invalidate the any presence of multi-collinearity. A Durbin-Watson value of 2.017 also invalidated the presence of independent errors (Asteriou and Hall, 2007).

\section{Factor Analysis}

Exploratory Factor Analysis (EFA): As an essential theory-generating procedure (Khong \& Richardson, 2003), EFA was used to summaries the data and to reduce it to lesser set of new factors with slightest loss of information. Consequently, the result from this analysis extracted five factors, after suppressing factor loadings (absolute values) that are less than 0.4.

Table1: KMO and Bartlett's Test

\begin{tabular}{lll}
\hline Kaiser-Meyer-Olkin Measure of Sampling Adequacy. & $\mathbf{. 8 0 6}$ \\
\hline Bartlett's Test of Sphericity & Approx. Chi-Square & 12661.037 \\
& DF & 1431 \\
& Sig. & .000 \\
\hline
\end{tabular}

Table 2: Rotated Component Matrix

\begin{tabular}{|c|c|c|c|c|c|}
\hline & $\begin{array}{l}\text { Factor } \\
1\end{array}$ & 2 & 3 & 4 & 5 \\
\hline $\mathrm{F} 2$ & .845 & & & & \\
\hline F1 & .821 & & & & \\
\hline F5 & .781 & & & & \\
\hline F6 & .779 & & & & \\
\hline F3 & .759 & & & & \\
\hline $\mathrm{F} 4$ & .724 & & & & \\
\hline C1 & & .804 & & & \\
\hline $\mathrm{C} 2$ & & .803 & & & \\
\hline C5 & & .791 & & & \\
\hline $\mathrm{C} 4$ & & .781 & & & \\
\hline C6 & & .768 & & & \\
\hline C3 & & .733 & & & \\
\hline E6 & & & .847 & & \\
\hline E5 & & & .835 & & \\
\hline E2 & & & .815 & & \\
\hline E1 & & & .800 & & \\
\hline E3 & & & .738 & & \\
\hline E4 & & & .541 & & \\
\hline B5 & & & & .811 & \\
\hline B3 & & & & .785 & \\
\hline B2 & & & & .777 & \\
\hline
\end{tabular}


B6

B1

B4

G1

G6

G4

G3

G5

G2
.746

.730

.710

Note: Extraction Method: Principal Component Analysis. Rotation Method: Varimax with Kaiser Normalization.

One unique feature of EFA was the fragmented nature of the cross-loadings in which some variables manifested more than one factors. However, when factors with loadings more than 0.5 were highlighted to represent the variables, EFA yielded five factors (Table 2), with only three similar to the five dimensions measuring CSFs of BPR in Al-Mashari and Zairi (1999) and Bontis (1998). Based on the EFA output, the extracted factors were Factor 2 "organizational structure", Factor 3 "IT Infrastructure", and Factor 4 "Management competence and support". Factor 1 represented "operational performance" and Factor 5 "profitability". A recalculated coefficient alpha $(\alpha)$ value of 0.912 was also achieved. This indicated an acceptable reliability of the measuring tool. In addition, Kaiser, Meyer and Ohlin (KMO) measure of sampling adequacy (that is $0.806>0.5$ ), as depicted in table 1 , also indicated that the sample that was used to generate data was adequate and factorable (Khong \& Richardson, 2003). Table 3 shows the descriptive statistics and correlation matrix of all the constructs. It is important to note that none of the explanatory variables were strongly correlated. The mean and standard deviation were normally distributed (Panneerselvan, 2010). The alpha coefficient estimates are robust in its estimations. Consequently, all the variables were used in our analysis.

Table 3: Results of Factors Correlation and Scale Reliability with Descriptive Analysis

\begin{tabular}{lllllllll} 
Variables & Mean & \multicolumn{2}{l}{ Std. Deviation 1 } & $\mathbf{2}$ & $\mathbf{3}$ & $\mathbf{4}$ & $\mathbf{5}$ \\
\hline 1 Organisational Structure & 15.5000 & 4.94572 & $\mathbf{( . 8 9 1 )}$ & &. & & & \\
2 Operational Performance & 17.1517 & 5.18143 & $.232^{* *}$ & $\mathbf{( . 8 9 2 )}$ & & & & \\
3 Mgt Support \& Competence & 18.0000 & 6.41888 & $.315^{* *}$ & $.342^{* *}$ & $\mathbf{( . 8 8 1 )}$ &. & & \\
4 Profitability & 17.0274 & 5.52318 & $.204^{* *}$ & $.175^{* *}$ & $.294^{* *}$ & $\mathbf{( . 8 5 6 )}$ & \\
5 IT Infrastructure & 11.6343 & 4.65553 & $.296^{* *}$ & $.234^{* *}$ & $.204^{* *}$ & $.209^{* *}$ & $\mathbf{( . 8 8 8 )}$ \\
\hline
\end{tabular}

Note: ${ }^{* *}$ Correlation is significant at the 0.01 (2-tailed), ${ }^{*}$ correlation is significant at the 0.05 (2-tailed). Alpha coefficient estimates are presented in the diagonal.

Although the new conceptual framework appears to be a good tool to use (Khong \& Richardson, 2003), it is however preliminary and was subjected to the next analysis. This is on the premise that EFA only defines the relationships between factors and its variables however, to confirm the relationships CFA was used in this study.

Confirmatory Factor Analysis (CFA): According to Khong and Richardson (2003), CFA is a theory-testing procedure. Consequently, using the output of our EFA, our study leveraged on IBM SPSS Amos' interface to run a CFA. It was also an attempt to examine the reliability and validity of the measurement model (Hair et al. 1995). Although EFA allows the variables to define the nature of the factors, CFA specifies and confirms the relationships of the variables prior to the analysis (Panneerselvan, 2010). With total control of variables at this stage, each of the five factors (contrived during EFA) was allotted to represent the factors. Consequently, variables above 0.5 loadings were assigned to represent the various factors. However, variables less than 0.5 were subsequently constrained to zero (Hair et al., 1995). Variables retained are shown in Figure 2 
(Measurement model-i.e. confirmatory factor analysis). Five constructs were identified: three explanatory variables (organizational structure, IT Infrastructures, and management competence and support), one mediating variable (operational performance), and one dependent variable (profitability). Based on the output of the CFA (Figure 2), all factor loadings were found to be positive, large, oscillating from 0.60 to 0.89 and highly significant $(\mathrm{p}<0.001)$, this however, confirmed the validity of the measurement model, i.e. CFA (Panneerselvan, 2010).

Table 4: Summary of Test Result-Reliability Analysis

\begin{tabular}{|c|c|c|c|c|}
\hline Constructs & $\begin{array}{l}\text { Number of } \\
\text { Questionnaire } \\
\text { items }\end{array}$ & $\begin{array}{l}\text { Cronbach's } \\
\text { Alpha } \\
\text { (mean) }\end{array}$ & $\begin{array}{l}\text { Composite } \\
\text { Reliability } \\
\text { (CR) }\end{array}$ & $\begin{array}{l}\text { Average Variance } \\
\text { Extracted (AVE) }\end{array}$ \\
\hline Organizational structure & 6 & 0.923 & 0.895 & 0.786 \\
\hline $\begin{array}{l}\text { Management competence } \\
\text { and support }\end{array}$ & 6 & 0.890 & 0.913 & 0.873 \\
\hline IT Infrastructures & 5 & 0.894 & 0.844 & 0.735 \\
\hline $\begin{array}{l}\text { Operational performance } \\
\text { Profitability }\end{array}$ & $\begin{array}{l}6 \\
6\end{array}$ & $\begin{array}{l}0.922 \\
0.932\end{array}$ & $\begin{array}{l}0.733 \\
0.724\end{array}$ & $\begin{array}{l}0.778 \\
0.734\end{array}$ \\
\hline
\end{tabular}

Figure: 2 CFA (Measurement Model)

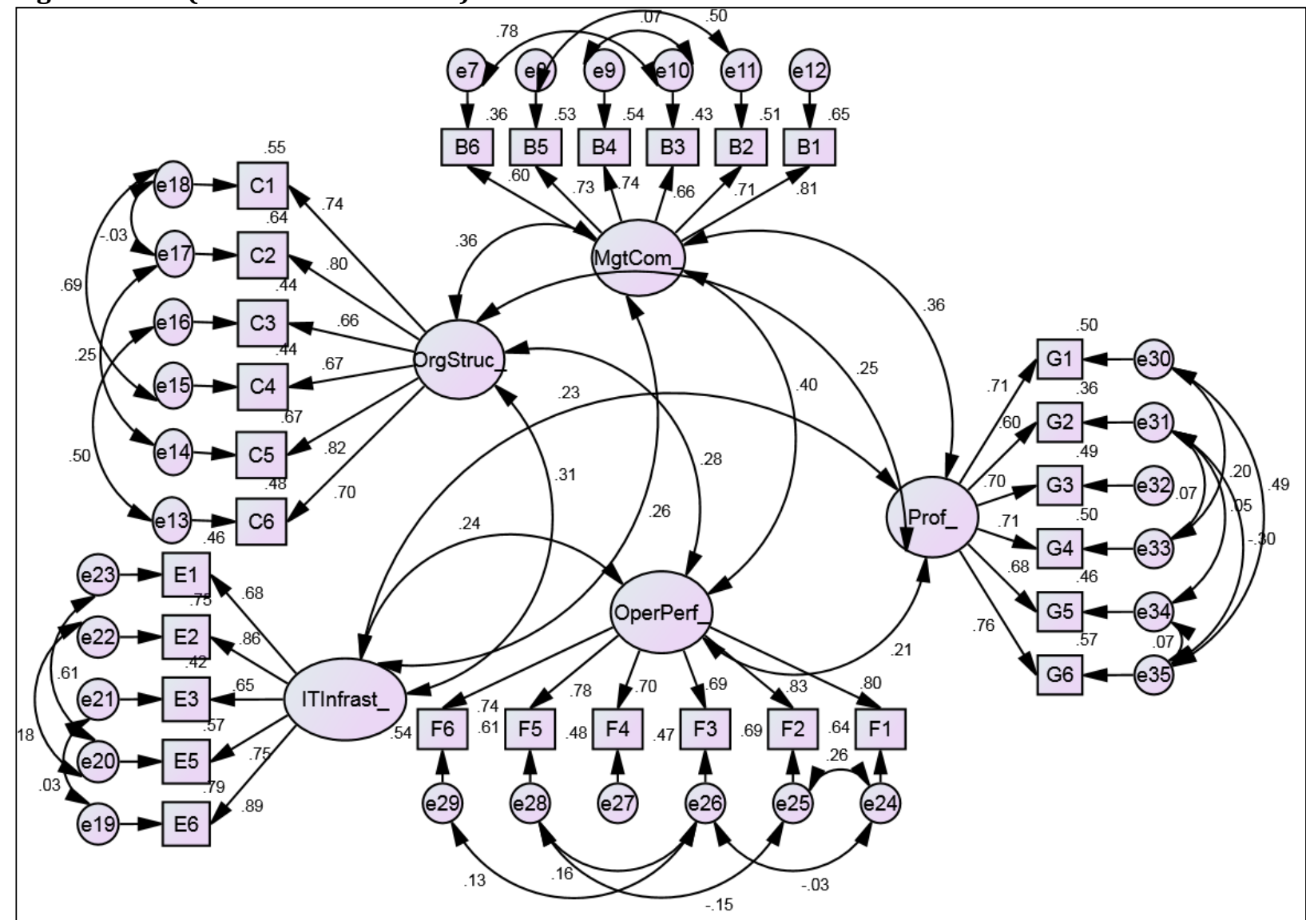

The reliability of the various constructs is shown in table 4. The Cronbach's coefficient alphas $(\alpha)$ of all the constructs are well above the recommended thresholds, depicting the consistency of the dataset (Hair et al., 1995). 
Model Fit-CFA: To demonstrate the overall fit of our measurement model and the construct validity of variables, various model fit indices were utilised (Ho, 2000; Anderson \& Gerbing, 1988). Consequently, the indices used to interpret the results were: chi-square (CMIN), normed-chisquare value (CMIN/DF) or X2/df ratio, the root mean square Error of Approximation (RMSEA), the comparative fit index (CFI), the goodness of fit index (GFI), Tucker-Lewis Index (TLI)- also known as Non-Normed Fit Index (NNFI), Normed Fit Index (NFI), Incremental Fit Index (IFI) (Schumacker \& Lomax 1996; Hair et al. 1995; Byrne 2001; Baumgartner \& Homburg 1996). Based on literature, once at least four indices are good, one can conclude a good model fit (Fields \& Atiku, 2015; Khong \& Richardson, 2003). The results of the fit indices are shown in Table 5.

Table 5: Goodness of Fit Indices for the CSFS of BPR Model

\begin{tabular}{lll}
\hline Goodness of fit indices & Fit Criteria & CSFs of B \\
\hline$X^{2}$ & & 588.957 \\
DF & & 354 \\
$p$ & $<3$ & $<0.00$ \\
$X^{2} /$ DF & $=0.08$ & 1.664 \\
RMSEA & $=0.9$ & 0.041 \\
CFI & $=0.8$ & 0.966 \\
GFI & $=0.8$ & 0.911 \\
AGFI & $=0.9$ & 0.891 \\
TLI & $=0.9$ & 0.95 \\
NFI & $=0.9$ & 0.95 \\
IFI & & 0.96
\end{tabular}

Adapted from Hair et al. 1995, Schumacker \& Lomax 1996, Baumgartner \& Homburg 1996, Byrne 2001

The Normed $\mathrm{X}^{2}$ or $\mathrm{X}^{2} / \mathrm{DF}$ ratio (CMIN), measures the degree of inconsistency between the sample and covariance matrices; however, since 1.664 falls within 1 to 2, it indicates acceptable model fit between the CSFs of BPR and the sample data (Schumacker \& Lomax 1996). In addition, the root mean square Error of Approximation (RMSEA) value of $0.041<0.05$ indicated a good fit with the population covariance (Hair et al., 1995). Furthermore, the comparative fit index (CFI) value of 0.966 indicated a perfect model fit, in terms of the adequacy of the sample size (Baumgartner \& Homburg 1996). Both the GFI and AGFI, at 0.911 and 0.891 , were above the recommended 0.8. This implied a good fit of the measurement model (Fields \& Atiku, 2015). The Normed Fit Index (NFI) at 0.95 also represented a good incremental fit index (Byrne 2001). Other model fit indices, like, Tucker-Lewis Index (TLI)- also known as Non-Normed Fit Index (NNFI), and the Incremental Fit Index (IFI) were well above the recommended minimum of 0.9. These are an indication of good fit (Hair et al. 1995). The results indicated uni-dimensionality and good fit with our data (Hair et al., 1995).

Structural Equation Modelling (SEM): The second objective of this paper was the testing of the contrived model, by evaluating the relationships between the CSFs of BPR and profitability, giving the mediating influence of operational performance. This was achieved via SEM. Using the output of our SEM, via IBM SPSS Amos' user-friendly interface; we drew on our contrived models to examine the relationships among CSFs of BPR, operational performance and profitability. According to Fields and Atiku (2015), AMOS is designed to test SEM and determine the linear relationships among latent and manifest variables. It is also designed to confirming correlations and inferred causal relationships among factors (Khong \& Richardson, 2003). However, after performing CFA, SEM (with AMOS) was helpful in analyzing the theoretical framework developed during CFA, to establish the extent to which operational performance mediates the relationship between CSFs of BPR and profitability (Fields \& Atiku, 2015; Khong \& Richardson, 2003). The structural model as illustrated in Figure 3 shows that organizational structure has an impact on profitability and operational performance.

IT Infrastructure also has an impact on both operational performance and profitability. However, SEM failed to establish the relationship between management competence and support and profitability. That notwithstanding, operational performance perfectly mediated the relationship between management 
competence and support and profitability. In all, operational performance perfectly mediated the relationship between CSFs of BPR and profitability. The last stage of this study was the testing of our contrived model. This was done by assessing the standardized regression weights for latent and manifest variables (Khong \& Richardson, 2003). The standardized regression weights for the CSFs of BPR and the performance measures (operational performance and profitability) are shown in Table 6. The result shows all standardized regression path estimates or beta loading from the performance measures (operational performance and profitability) to the various CSFs of BPR. The entire beta loading were significant at $0.05 \%$ level of significance (Khong \& Richardson, 2003). The mediating influence of operational performance was highly noticeable in the relationship between management competence and support and profitability.

\section{Fig 3: SEM and Hypothesis Testing using AMOS}

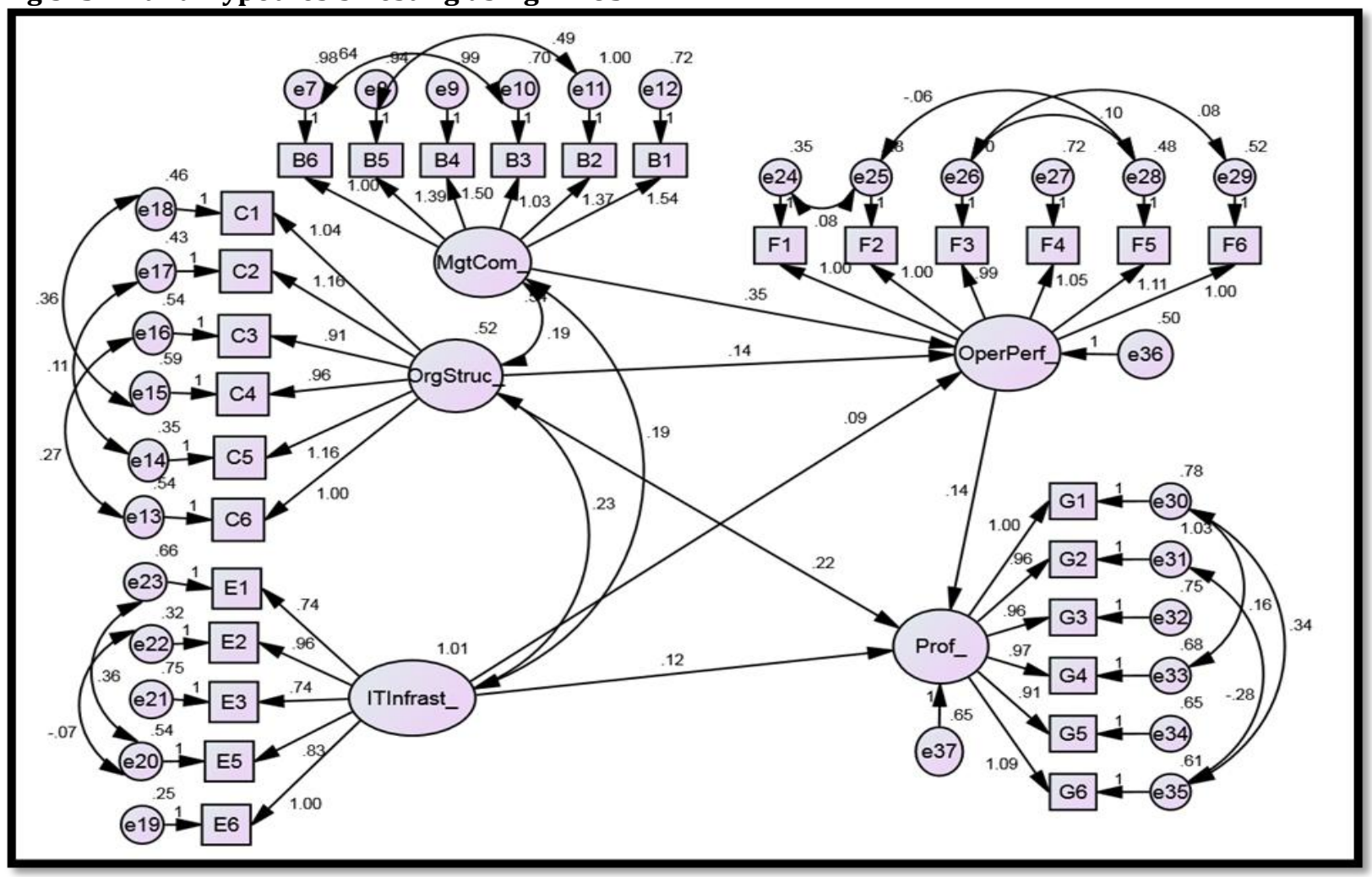

Similar with the CFA, the fit indices for the SEM were acceptable. Consequently, the identified model fits our empirical data. Specifically, the comparative fit index (CFI) (at 0.96) and the Tucker-Lewis index (TLI) (at 0.97) were greater than the recommended 0.95 , and the root mean square error of approximation (RMSEA) was also smaller (at 0.48) than the recommended 0.08 (Byrne 2001). One of the major advantages of the SEM in Figure 3 is the opportunity of graphically viewing the inferred causal relationships between the CSFs of BPR, operational performance, and profitability (Byrne 2001; Hsu, 2010). Consequent, upon the establishment of a good SEM fit indices; this implies that the underlined dimensions of the various factors are valid (Byrne 2001). Consequently, our model shows the mediating influence of operational performance on the interplay between profitability (organizational performance) and CSFs of BPR.

Table 6: Standardized Regression Weights

\begin{tabular}{|c|c|c|c|c|c|c|c|}
\hline & & & Estimate & S.E. & C.R. & $\mathbf{P}$ & Label \\
\hline OperPerf_ & $<---$ & MgtCom_ & .346 & .070 & 4.961 & $* * *$ & par_42 \\
\hline OperPerf_ & $<---$ & ITInfrast_ & .090 & .044 & 2.047 & .041 & par_45 \\
\hline OperPerf_ & $<---$ & OrgStruc_ & .140 & .068 & 2.072 & .038 & par_47 \\
\hline Prof_ & $<---$ & OrgStruc_ & .219 & .076 & 2.893 & .004 & par_43 \\
\hline
\end{tabular}




\begin{tabular}{|c|c|c|c|c|c|c|c|}
\hline & & & Estimate & S.E. & C.R. & $\mathbf{P}$ & Label \\
\hline Prof_ & $<---$ & ITInfrast_ & .124 & .051 & 2.439 & .015 & par_44 \\
\hline Prof_- & $<---$ & OperPerf_ & .145 & .065 & 2.229 & .026 & par_46 \\
\hline B6 & $<---$ & MgtCom_ & 1.000 & & & & \\
\hline B5 & $<---$ & MgtCom_ & 1.390 & .125 & 11.103 & $* * *$ & par_1 \\
\hline B4 & $<---$ & MgtCom_ & 1.504 & .142 & 10.577 & $* * *$ & par_2 \\
\hline B3 & $<---$ & MgtCom_ & 1.028 & .048 & 21.399 & $* * *$ & par_3 \\
\hline B2 & $<---$ & MgtCom_ & 1.365 & .126 & 10.803 & $* * *$ & par_4 \\
\hline B1 & $<---$ & MgtCom_ & 1.543 & .140 & 11.020 & $* * *$ & par_5 \\
\hline C6 & $<---$ & OrgStruc & 1.000 & & & & \\
\hline C5 & $<---$ & OrgStruc & 1.161 & .090 & 12.851 & $* * *$ & par_6 \\
\hline $\mathrm{C} 4$ & $<---$ & OrgStruc_ & .960 & .083 & 11.566 & $* * *$ & par_7 \\
\hline C3 & $<---$ & OrgStruc & .905 & .055 & 16.569 & $* * *$ & par_8 \\
\hline $\mathrm{C} 2$ & $<---$ & OrgStruc_ & 1.159 & .093 & 12.412 & $* * *$ & par_9 \\
\hline $\mathrm{C} 1$ & $<---$ & OrgStruc & 1.039 & .082 & 12.744 & $* * *$ & par_10 \\
\hline E6 & $<---$ & ITInfrast_ & 1.000 & & & & \\
\hline E5 & $<---$ & ITInfrast_ & .831 & .050 & 16.645 & $* * *$ & par_11 \\
\hline E3 & $<---$ & ITInfrast_ & .741 & .051 & 14.648 & $* * *$ & par_12 \\
\hline E2 & $<---$ & ITInfrast_ & .958 & .045 & 21.489 & $* * *$ & par_13 \\
\hline E1 & $<---$ & ITInfrast_ & .744 & .050 & 14.988 & $* * *$ & par_14 \\
\hline F1 & $<---$ & OperPerf_ & 1.000 & & & & \\
\hline $\mathrm{F} 2$ & $<---$ & OperPerf_ & 1.001 & .050 & 20.021 & $* * *$ & par_15 \\
\hline F3 & $<---$ & OperPerf_ & .991 & .076 & 13.081 & $* * *$ & par_16 \\
\hline $\mathrm{F} 4$ & $<---$ & OperPerf & 1.050 & .075 & 14.051 & $* * *$ & par_17 \\
\hline F5 & $<---$ & OperPerf_ & 1.111 & .073 & 15.174 & $* * *$ & par_18 \\
\hline F6 & $<---$ & OperPerf_ & .996 & .067 & 14.828 & $* * *$ & par_19 \\
\hline G1 & $<---$ & Prof_- & 1.000 & & & & \\
\hline G2 & $<---$ & Prof & .965 & .091 & 10.588 & $* * *$ & par_20 \\
\hline G3 & $<---$ & Prof_- & .965 & .081 & 11.956 & $* * *$ & par_21 \\
\hline G4 & $<---$ & Prof_- & .970 & .072 & 13.399 & $* * *$ & par_22 \\
\hline G5 & $<---$ & Prof_- & .909 & .076 & 11.900 & $* * *$ & par_23 \\
\hline G6 & $<---$ & Prof_- & 1.087 & .062 & 17.432 & $* * *$ & par_24 \\
\hline
\end{tabular}

For instance, the direct paths from CSFs of BPR to operational performance $(0.346,0.090$, and 0.140$)$ in the structural model were statistically significant at $0.05 \%$ level ( $p$ values of $0.000,0.041$, and 0.038 ), a validation of Ho: hypothesis. Furthermore, the direct paths from CSFs of BPR to profitability $(0.219,0.124$, and 0.145 respectively) in the structural model were also statistically significant at $0.05 \%$ level ( $p$ values of 0.004 , 0.015, and 0.026 respectively), a validation of $\mathbf{H o}_{2}$ : hypothesis. Therefore, the SEM posits the positive effect of the CSFs of BPR implementations on the two performance measures (operational performance and profitability).

Discussion of Findings: This study revealed that the underlying dimensions of the CSFs of BPR implementations in the Nigerian oil and gas industry are organizational structure, management competence and support, and IT infrastructures. The outcome of the CFA posit that all three dimensions of the CSFs of BPR contributed significantly to operational performance and profitability in the Nigerian oil and gas industry. Specifically, the structural model also shows the positive effect of organizational structure and IT Infrastructures on both profitability and operational performance. However, SEM failed to establish the relationship between management competence and support and profitability. That notwithstanding, 
operational performance also perfectly mediated the relationship between management competence and support and profitability. Based on our findings, our model could be generalized to other manufacturing industries. By confirming our models empirically using SPSS Statistics and Amos, oil and gas companies can favourably determine the relationships between performance measures (e.g. profitability and operational performance) and the CSFs of BPR (Hsu, 2010; Fields \& Atiku, 2015; Khong \& Richardson, 2003). This is on the premise that both the CFA and SEM in our study showed a good model fit and can therefore be seen as a reliable and valid model to use to measure successful BPR implementations in the oil and gas industry. The significant positive relationships obtained in this study are similar to previous findings (Ascari et al., 1995; Smith, 2003; Ahmed et al., 2007).

This study also supports Salaheldin (2009) proposition that enriched structures, processes, and technology is capable of reducing a company's risk of failure in any BPR implementation programme. The mediating influence of operational performance also collaborate the significant influence of improved BPR on a company's performance indices (Abdolvand et al., 2008). Consequently, operational performance indicators would lead to successes in secondary measures of performance (Ahmed et al., 2007; Salaheldin, 2009). However, it is also important to note that not all of the variables in CSFs were effectively affecting profitability and operational performance in the Nigerian oil and gas industry. Specifically, based on the results of the EFA, variables manifesting change of management system and culture, BPR-project management, and some business performance measures were omitted from our analyses due to their inability to meet the setting of 0.5 thresholds (Hair et al., 1995).

Consequently, based on our findings, for BPR implementation to be successful in the Nigerian oil and gas companies, there should be adequate commitment and support from the top Management. In addition, there should be constant BPR risk and performance evaluation to access the extent of change management techniques. There is also need to create new organizational structures to determine the composition of BPR teams. Other top prerequisites for a successful BPR implementation are as follows: management of reengineering leaders, champions, and project managers; effective leadership; adequate authority and responsibilities, knowledge transfers, and proper interaction with all stakeholders; experienced BPR champions and teams; adequate composition of BPR teams; suitable investment in information technology; and lastly, continuous measurement and control of information technology infrastructure capabilities.

\section{Conclusion and Implications of Findings}

Conclusion: In this study, a conceptual framework and model was created to identify the CSFs of BPR and its relationships with both profitability and operational performance in the Nigerian oil and gas industry. However, the novelty of this study lies in exploring the mediating influence of the operational performance on profitability. Specifically, findings based on the EFA, CFA and SEM revealed that CSFs of BPR positively influenced both operational performance and profitability in the Nigerian oil and gas industry. In addition, the study revealed that the underlying dimensions of successful BPR implementations are organizational structure, management competence and support, and IT infrastructures. Moreover, results of the CFA suggest that all three dimensions of CSFs of BPR contribute significantly to operational performance and profitability. The structural model also shows the positive effect of organizational structure and IT Infrastructures on both profitability and operational performance. The only surprising result was the inability of SEM to establish the relationship between management competence and support and profitability. That notwithstanding, operational performance still mediated the relationship between management competence and support and profitability. Based on our findings, our model could be generalized to other manufacturing industries (Hsu, 2010; Fields \& Atiku, 2015; Khong \& Richardson, 2003). Therefore, the contrived model in this study is proposed as a model to measure successful BPR implementation in the Nigerian oil and gas industry. This is on the premise that both CFA and SEM showed a good overall model fit.

Implications of Findings: Our study seems to be one of the few scrutinizing the success of BPR implementations, and its related CSFs, from the standpoint of how organizations fare after implementing BPR efforts. This gap was originally highlighted by Al-Mashari and Zairi (1999: 105). According to Al-Mashari (2003), despite increasing investments in BPR efforts by organizations around the world, proper efforts to determine their accomplishment and the fundamental causes have been very limited. Al-Mashari and Zairi 
(1999) also advocated for the scrutiny of critical factors involved in BPR implementations. Lastly, in terms of relationship, this study corroborates that there are particular CSFs of BPR implementation efforts that are related to business improvements (Ahmed et al., 2007). Another important contribution of our study was the measurement of business performance, which was not restricted to financial measures, but incorporates varied business measures, like profitability and operational performance (Khong and Richardson, 2003). Development of our CFA and SEM also filled a gap identified by Ahmed et al. (2007), that much effort is required in contriving a model for BPR implementations. Furthermore, our study lends a theoretical model for emerging a combined model toward examining the relationship between CSFs of BPR implementations, BPR effectiveness (operational performance) and BPR success (profitability). Moreover, the corroborated findings provide valuable implications for practice.

This study is expected to provide specific direction to companies contemplating a BPR programme, hence, the study is expected to be beneficial to the oil and gas companies and policy makers by enabling better strategic and tactical judgments with regards to BPR implementations. According to Brown (2006; p. 20), due to the fundamental difference between EFA (EFA "is an exploratory analysis because no a priori restrictions are placed on the pattern of relationships between the observed measures and the latent variables") and CFA (in CFA, "the researcher must specify in advance several key aspects of the factor model such as the number of factors and patterns of indicator-factor loadings"), this study adopted CFA, because results obtained from EFA alone can be unreliable (Hsu, 2010; Khong \& Richardson, 2003). Another methodological implication of our study was the improvements over Awolusi (2013a) study. This is on the premise that unlike regression analysis which can only evaluate one equation at a time, the use of IBM SPSS Amos and SEM in our study allowed the examination of more than one regression equation or relationship at one time (Khong \& Richardson, 2003). Consequently, using SEM was more realistic, since it also takes potential measurement errors into account (Hsu, 2010; Fields \& Atiku, 2015).

Limitations and Directions for Future Research: One important limitation of this study is using perceptual data provided by senior and management staff which may not provide clear measures of profitability. Although the measurement models posited good fits, supplementary procedures might be used in future studies to minimize this potential limitation. These may include the use of objective measures like turnover, gross or net profit to measure the dependent and mediating variables. The use of manifold raters from different classes, such as consultants/ experts and customers may also be encouraged in future studies. Given diverse measures of the explanatory variables (CSFs of BPR) in previous studies, it is important that our proposed CSFs and the output may represent various levels of generalization. Nevertheless, these limitations posit restraint in generalizing the results of this study. That notwithstanding, the affirmation of our models, via various statistical packages and techniques, confirmed the efficacy and reliability of our model. Future studies may also consider the inclusion of BPR implementations in more countries. It is also important to state that the omitted variable (CSFs), due to the setting of 0.5 thresholds, does not make a factor less important to the current study, and as such this factor should be interpreted with this possible constraint in mind (Fields \& Atiku, 2015; Khong \& Richardson, 2003).

\section{References}

Abdolvand, N., Albadvi, A. \& Ferdowsi, Z. (2008). Assessing readiness for business process reengineering, Business Process Management Journal, 14(4), 497-511.

Adeyemi, S. \& Aremu, M. A. (2008). Impact assessment of Business Process Reengineering on Organizational performance, European Journal of Social Sciences, 7(1), 115-125.

Ahmed, H., Francis, A. \& Zairi, M. (2007). Business process reengineering: Critical success factors in higher education, Business Process Management Journal, 13(3), 451-469.

Al-Mashari, M. (2003). Enterprise Resource Planning (ERP) systems: A research agenda, Industrial Management \& Data Systems, 103(1), 22-27.

Al-Mashari, M. \& Zairi, M. (1999). BPR implementation process: an analysis of Key success and failure factors, Business process Management Journal, 5(1), 87-112.

Al-Mashari, M., Irani, Z. \& Zairi, M. (2001). Business Process Reengineering: a survey of international experience, Business process Management Journal, 10(4), 437-455. 
Anderson, J. \& Gerbing, W. (1988). Structural equation modeling in Practice: A review and recommended two stage approach. Psychological Bulletin, 27(1), 5-24.

Ascari, A., Rock, M. \& Dutta, S. (1995). Reengineering and organisational change: lessons from a comparative analysis of company experience, European Management Journal, 13(1), 1-30.

Asika, N. \& Awolusi, O. D. (2013). Modeling Critical Success Factors of Business Process Re-engineering and Business Performance of Nigerian Oil and Gas Companies, International Journal of Services and Operations Management, 15(1), 28-43.

Asikhia, U. O. \& Awolusi, O. D. (2015). Assessment of Critical Success Factors of Business Process Reengineering in the Nigerian Oil and Gas Industry, South African Journal of Business Management, $46(2), 1-14$

Asteriou, D. \& Hall, S. G. (2007). Applied Econometrics: A Modern approach. (Revised Edition), NY: Palmgrave Macmillan.

Awolusi, O. D. (2013a). Assessment of Critical Success Factors of Business Process Re-engineering in Nigerian Oil and Gas Industry, Unpublished PhD Thesis, Ilishan-Remo: Babcock University.

Awolusi, O. D. (2013b). Effects of motivation on employee job commitment in the Nigerian banking industry: an empirical analysis, International Journal of Business and Innovation Research, 1(3), 1-17.

Awolusi, 0. D. (2013c). The effects of total quality management on customer service management in the Nigerian banking industry: an empirical analysis, International Journal of Management and Network Economics, 3(1), 57-77.

Baumgartner, H. \& Homburg, C. (1996). Applications of structural equation modeling in marketing and consumer research: A review. International Journal of Research in Marketing, 1(13), 139-161.

Bhatt, G. D. (2000). Exploring the relationship between information technology, infrastructure and business process re-engineering, Business Process Management, 6(2), 139-63.

Bontis, N. (1998). Intellectual capital: an exploratory study that develops measures and models, Management Decision, 36(2), 63-7.

Brouthers, K. D. \& Hennart, J. (2007). Boundaries of the Firm: Insights from International Entry Mode Research, Journal of Management, 33(3), 395-425.

Brown, T. A. (2006). Confirmatory Factor Analysis for Applied Research, New York, NY: Guilford Press.

Byrne, B. (2001). Structural equation modeling with AMOS. New Jersey: Lawrence Erlbaum Associate

Cabin, R. \& Grant, R. M. (1996). Restructuring among the world's largest oil majors, British Journal of Management, 4(3), 212-235.

Chiplunkar, S. G., Deshmukh, H. \& Chattopadhyay, R. (2003). Application of principles of event related open systems to business process reengineering, Computers \& Industrial Engineering, 45(3), 347-374.

Davenport, T. H. (1993a). Need radical innovation and continuous improvement? Integrate process reengineering and TQM, Planning Review, 21(3), 6-12.

Davenport, T. H. (1993b). Process Innovation: Reengineering Work through Information Technology, Harvard Business School Press, Boston, MA.

Dunning, J. H. (1993). Multinational enterprises and the global economy. Wokingham, UK: Addison-Wesley.

Fields, Z. \& Atiku, S. O. (2015). Testing and operationalizing a model to measure Creativity at Tertiary Educational Level, International Journal of Educational Sciences, 9(3), 283-296.

Hall, G., Rosenthal, J. \& Wade, J. (1993). How to make reengineering really work, Harvard Business Review, 71(6), 119-31.

Hammer, M. (1990). Reengineering work: don't automate, obliterate, Harvard Business Review, 68(4), 104-12.

Hammer, M. \& Champy, J. (1993). Reengineering the corporation: a manifesto for business revolution, Harper Business, New York, NY.

Hair, J., Anderson, R., Tatham, R. \& Black, W. (1995). Multivariate Data Analysis with Readings, Englewood Cliffs: Prentice-Hall International.

Hancock, G. R. \& Mueller, R. 0. (2001). Rethinking construct reliability within latent variable systems. In R. Cudeck, S., du Toit. \& Srbom D. (Eds.), Structural Equation Modeling: Present and Future -Festschrift in honor of Karl Jreskog (pp. 195-216). Lincolnwood, IL: Scientific Software International, Inc.

Hoopes, D. G., Madsen, T. L. \& Walker, G. (2003). Guest Editors' Introduction to the Special Issue: Why is there a Resource-Based View? Toward a Theory of Competitive Heterogeneity, Strategic Management Journal, 24(1), 889-902. 
Hsu, M. K. (2010). Structural Equation Modeling with IBM SPSS Amos: A methodology for predicting behavioral intentions in the services sector, IBM Software Business Analytics, IBM Corporation: NY 10589.

Ho, R. (2000). Handbook of Univariate \& Multivariate Data Analysis \& Interpretation: SPSS Approach. Rockhampton: Central Queensland University.

Iles, V. \& Sutherland, K. (2001). Managing Change in the NHS: Organisational change- a review for Health care Managers, Professionals and Researchers, London: National Coordinating Centre for NHS Service Delivery and Organisation.

Khodakaram, S., Mohammad, A. A. \& Ahmad, G. (2010). Interpretive Structural Modeling of Critical Success Factors in Banking Process Re-engineering, International Review of Business Research Papers, 6(2), 95-103.

Khong, K. W. \& Richardson, S. (2003). Business process re-engineering in Malaysian banks and finance companies, Managing Service Quality, 13(1), 54-71.

Maldonado, M. (2009). Factors impacting the Success of ERP Implementations in Small and Medium Enterprises: An empirical assessment from Latin America. ESADE PhD in Management Sciences Program.

Mustapha, A. M., Fakokunde, T. O. \& Awolusi, O. D. (2014). The Quick Service Restaurant Business in Nigeria: Exploring the Emerging Opportunity for Entrepreneurial Development and Growth, Global Journal of Commerce and Management Perspective, 3(3), 8-14.

Ovenden, T. (1994). Business process re-engineering: definitely worth considering, The TQM Magazine, 6(3), 56-61.

Ozcelik, Y. (2010). Do business process reengineering projects payoff? Evidence from the United States, International Journal of Project Management, 28(3), 7-13.

Panneerselvam, R. (2010). Research Methodology, New Delhi.

Porter, M. E. (1980). Competitive strategy: technique for analyzing industries and competitors. New York: Free Press.

Ranganathan, C. \& Dhaliwal, J. S. (2001). A survey of business process reengineering practices in Singapore, Information and Management, 39(2), 125-34.

Richard, C. E. (1992). American Industry: Structure, Conduct, Performance, Prentice Hall, 7th E, 3-36.

Ringim, K. J., Razalli, M. R. \& Hasnan, N. (2011). Effect of Business Process Reengineering factors on organizational performance of Nigerian banks: Information Technology capability as the moderating factor, International Journal of Business and Social Science, 2(13), 198-201.

Rumelt, R. P. (1991). How much does industry matter? Strategic Management Journal, 12(3), 167-185

Salaheldin, I. S. (2009). Critical success factors for TQM implementation and their impact on performance of SMEs, International Journal of Productivity and Performance Management, 58(3), 215-237.

Schumacker, R. \& Lomax, R. (1996). A Beginner Guide to Structural Equation Modelling. Mahwah, New Jersey: Lawrence Erlbaum Association.

Smith, M. (2003). Business process design: correlates of success and failure, The Quality Management Journal, 10(2), 38-49.

Tilley, S. (1996). Perspectives on legacy system reengineering, Mellon: Reengineering centre, software Engineering Institute, Carnegie Mellon University. 